\title{
El tráfico de drogas como delito internacional conforme al Estatuto de Roma: el caso mexicano
}

The drug trafficking as international crime according to de Rome's

Statute: the mexican case

Autor: Antonio Olguín Torres

DOl: https://doi.org/10.25058/1794600X.1043

\footnotetext{
Ś MISIÓN JURÍDICA A
} 


\title{
EL TRÁFICO DE DROGAS COMO DELITO INTERNACIONAL CONFORME AL ESTATUTO DE ROMA: EL CASO MEXICANO*
}

\author{
The drug trafficking as international crime according to \\ de Rome's Statute: the mexican case \\ Tráfico de drogas como crime internacional sob o \\ Estatuto de Roma: o caso mexicano
}

Antonio Olguín Torres ${ }^{a}$

aolguint@ugto.mx

Fecha de recepción: 03 de julio de 2019

Fecha de revisión: 05 de julio de 2019

Fecha de aceptación: 19 de agosto de 2019

\section{RESUMEN}

DOI: https://doi.org/10.25058/1794600X.1043

Para citar este artículo:

Olguín, A. (2019). El tráfico de drogas como delito internacional conforme al Estatuto de Roma: el caso mexicano. Revista Misión Jurídica, 12, (17), 73-89.

El presente artículo de investigación plantea el problema jurídico que representa el considerar exclusivamente al delito de tráfico de drogas como nacional en el caso del Código Penal Federal mexicano, y las repercusiones que ello implica para aquellas conductas criminales que trascienden las fronteras de los Estados que hacen nugatorio el poder punitivo estatal, y que lo obliga a encontrar diversas soluciones para detener estas conductas criminales más allá de sus fronteras nacionales. Consecuentemente, la hipótesis de esta investigación es la propuesta de considerar al delito de tráfico de drogas, además de nacional, como un delito internacional, tipificado dentro de los delitos de lesa humanidad y, con ello, posibilitar a la Corte Penal Internacional para que pueda tener competencia para perseguir y sancionar aquellas conductas criminales graves que atenten en contra de la seguridad internacional.

\section{PALABRAS CLAVE}

Tráfico de drogas, delito internacional, México, Corte Penal Internacional, competencia.

\section{* Articulo de reflexión}

a. Doctor en Derecho con Mención Honorífica por la Universidad de Colima de México; Profesor Investigador de Tiempo Completo del Departamento de Derecho de la División de Derecho, Política y Gobierno de la Universidad de Guanajuato. Miembro del Sistema Nacional de Investigadores de México 


\section{ABSTRACT}

This research approaches the problem, as an object of investigation, that exists in the case of the Mexican Criminal Federal Code to consider drug trafficking exclusively as a national crime, and the implications that come with those criminal actions that cross the territorial borders of the countries and make nugatory the punitive power of the Mexican State to persecute and sanction these kind of criminal behaviours. This situation forces the Mexican authorities to find solutions to stop these conducts that cross the territorial borders of Mexico; therefore, the hypothesis of this research is to consider the crime of drug trafficking, as well as national, as an international crime and to allow the competence of the International Criminal Court to investigate and punish those grave criminal conducts that threaten international security.

\section{KEY WORDS}

Drug trafficking, international crime, México, International Criminal Court, competence.

\section{RESUMO}

Este artigo de pesquisa levanta o problema jurídico de considerar exclusivamente o crime de narcotráfico como nacional no caso do Código Penal Federal do México, e as implicações que isso implica para os comportamentos criminosos que transcendem as fronteiras dos Estados que praticam o crime. 0 poder do Estado punitivo é nugativo e o obriga a encontrar várias soluções para deter esses comportamentos criminosos além de suas fronteiras nacionais. Consequentemente, a hipótese desta investigação é a proposta de considerar o crime de narcotráfico, além de nacional, como crime internacional, tipificado nos crimes contra a humanidade e, com isso, permitir ao Tribunal Penal Internacional permitir ter competência para processar e punir aqueles comportamentos criminosos graves que atentam contra a segurança internacional.

\section{PALAVRAS CHAVE}

Tráfico de drogas, crime internacional, México, Tribunal Penal Internacional, jurisdição.

\section{INTRODUCCIÓN}

El planteamiento del problema de esta investigación parte del contexto internacional en el que se encuentra México, toda vez que tiene como vecinos en la parte norte a los Estados Unidos de América, uno de los principales consumidores de drogas; y en la parte sur, a Guatemala que sirve de tránsito para la droga que viene del sur del continente con destino a América del Norte; adicionalmente, a la droga que se produce en México. Esta problemática internacional permite plantear la siguiente pregunta de investigación ¿el tráfico de drogas es un delito internacional?

Ello se debe a que conforme al Código Penal Federal en el artículo 194 fracción I se encuentra tipificado el delito de tráfico de drogas, pero de igual forma en el artículo 5 del Estatuto de Roma se hace referencia en su párrafo primero inciso b) a los crímenes de lesa humanidad, mismos que son posteriormente conceptualizados en el artículo 7, que establece en su párrafo primero inciso k) que son delitos considerados como de lesa humanidad aquellos ataques generalizados y sistemáticos que atentan gravemente contra la salud mental o física de las personas, de tal manera, que la aportación de esta investigación es considerar al tráfico de drogas como un delito de lesa humanidad porque afecta la salud de las personas de manera sistemática y generalizada, y en los cuales la competencia de un solo Estado no impide su propagación y afectación a personas de distintas naciones.

De esta aseveración surge otra pregunta de investigación que se desprende de la anterior es ¿en qué casos el delito de tráfico de drogas es considerado como internacional? Esta investigación tiene como hipótesis que cuando el resultado de traficar con drogas sobrepasa el ámbito interno de los Estados, se debe considerar como un delito internacional, dado que los efectos que produce trascienden las fronteras nacionales, por lo tanto, son graves, pues afectan a dos o más poblaciones, lo que propicia una respuesta por parte de la comunidad internacional.

Esta hipótesis encuentra apoyo en lo señalado por el artículo 2 de la Convención de las Naciones Unidas Contra la Delincuencia Organizada (en adelante CNUCDOT) que establece que se considera como delito grave "la conducta que constituya un delito punible con una privación de libertad máxima de al menos cuatro años o con una 
pena más grave" (CNUCDOT: web), así como en el artículo 3 párrafo uno inciso a) de la Convención de las Naciones Unidas Contra el Tráfico Ilícito de Estupefacientes y Sustancias Psicotrópicas (en adelante CNUCTIESP) celebrado en Viena el 19 de diciembre de 1988; que establece que se considera como delito internacional "la oferta, la oferta para la venta, la distribución, la venta, la entrega en cualesquiera condiciones, el corretaje, el envío, el envío en tránsito, el transporte, la importación o la exportación de cualquier estupefaciente o sustancia psicotrópica" (CNUCTIESP: web), toda vez que el propósito de este tratado internacional, en los términos de su artículo 2, es la de "hacer frente con mayor eficacia a los diversos aspectos del tráfico ilícito de estupefacientes y sustancias psicotrópicas que tengan un alcance internacional" (CNUCTIESP: web). Este tratado internacional encuentra igual sustento en la Convención Única de 1961 sobre Estupefacientes y su Enmienda por el Protocolo de 1972 (en adelante CUSEyEP) que establece en su artículo 1 que se entiende por tráfico ilícito "el cultivo o cualquier tráfico de estupefacientes" (CUSEyEP: web), y en su artículo 35 se establecen las medidas de cooperación en la lucha contra el tráfico ilícito, y adquiere su carácter internacional, en términos del artículo 36, cuando se comete en diferentes países.

En el desarrollo de esta investigación que buscará la comprobación falseable de esta hipótesis, se abordará lo relativo a lo que debe entenderse como delito internacional en términos generales desde el marco teórico expuesto por el autor alemán Kai Ambos, luego, el concepto de tráfico de drogas conforme a la legislación mexicana, posteriormente se abordará lo que sobre el tráfico de drogas señala el Estatuto de Roma, la eficacia de éste y las implicaciones que tiene para México el reconocimiento de la jurisdicción de la Corte Penal Internacional, así como los distintos mecanismos de cooperación jurídica que son necesarios para una correcta persecución y sanción de este tipo de conductas criminales.

En la actualidad, estamos en presencia de los efectos de la globalización que permea todos los aspectos de la vida del ser humano, en lo económico, social, religioso, cultural, y por supuesto, jurídico. Se imitan modelos de comportamiento y se crea una homogeneidad, principalmente entre los Estados de una región determinada del planeta. Pero hay conductas antisociales de carácter penal que siendo considerados como tales en las legislaciones nacionales, como es el caso de México con el delito de tráfico de drogas, trascienden el ámbito territorial de un Estado en particular, consecuentemente, escapa de su jurisdicción, y por lo tanto, es muy difícil su persecución y sanción, pues se carecen de los elementos suficientes y necesarios para hacer frente a este flagelo internacional criminal que "va de la mano con la evolución de las sociedades modernas" (Guerrero Agripino, 2012, p. 55). A este tipo de delitos que sin ser internacionales en cuanto a su tipificación, trascienden las fronteras nacionales, se les denomina delitos internacionales latu sensu pues no están tipificados como tales en los instrumentos internacionales.

También existen delitos que son propiamente internacionales, aquellos que la comunidad internacional busca que sean sancionados, como los crímenes de guerra y los crímenes de lesa humanidad, en donde es "imputable la responsabilidad del individuo directamente por el ordenamiento internacional" (Badía Martí, 2008, p. 330). Es decir, se trata de delitos internacionales, strictu sensu, es decir, aquellos así descritos por un tratado internacional, previamente consentido y aprobado por los órganos facultados para tal fin por la Constitución de cada país, que en el caso de México, su negociación le corresponde al Presidente de la República en los términos previstos por la fracción X del artículo 89 de la Carta Magna mexicana, y al Senado de la República le compete su aprobación, conforme lo estipulado por la fracción I del artículo 76 de la misma Ley Fundamental mexicana.

Es en este último apartado, en donde recobra importancia el derecho internacional penal, en la génesis de instrumentos normativos que propician un entramado normativo capaz de institucionalizar internacionalmente la persecución de este tipo de conductas criminales que por su naturaleza son transnacionales, y que de ocurrir, afectan no sólo a un Estado en particular, sino también a la comunidad internacional en su conjunto. Tratados que una vez consentidos y aprobados se convierten en documentos vinculantes para las autoridades internas, de tal manera que el Estado en su interior tiene la obligación de observarlos, ya sea procurando los mecanismos adecuados para la persecución y sanción de este tipo de conductas criminales, definidas así en el ámbito internacional, así como la creación, modificación o adición de 
normas nacionales que lleven a la realidad los compromisos asumidos internacionalmente en materia penal.

Inclusive, el concepto de derecho internacional penal, se identifica con el de derecho penal internacional, distinción que no tiene ninguna importancia académica, toda vez que las características de esta rama especializada del derecho internacional tiene que ver con el tratamiento de aquellas conductas que trasciendan las fronteras nacionales, y que en este entendido, un solo Estado por sí sólo, es incapaz de contener, requiriendo de la actuación concertada de otros Estados para detener este flagelo social de carácter criminal en la era de la globalización. Lo cierto es que international criminal law has become a core element of international law (Brus, 2014, p. 360), es decir, el Derecho Internacional Penal se ha convertido en un elemento esencial del derecho internacional. 0 como lo expuso Badia Martí:

El derecho penal constituye por excelencia una potestad normativa del Estado con una vía de producción y aplicación de las normas muy específico, su contenido material responden, junto con las cuestiones específicas de técnica jurídica, a parámetros sociológicos, ideológicos y criminológicos muy concretos y que son acordes con una sociedad determinada. Sin embargo, la propia evolución de la sociedad globalmente considerada así como la evolución de la propia técnica jurídica ha potenciado la dimensión internacional de la materia (2008, p. 328).

Es así que el poder punitivo único de un sólo Estado, pensado en términos de fronteras nacionales, deja de ser el único mecanismo sancionador, pues se apoya en los mecanismos sancionadores de otros Estados, o bien de instituciones supranacionales, cuya cooperación jurídica internacional de carácter penal, surgen en virtud de la creación de tratados, fuente convencional positiva que permite establecer las convergencias entre Estados sobre aspectos de carácter penal, toda vez que las "vías de actuación jurídica [...] gira (n) en torno a: la incorporación de los tipos penales por la vía convencional y, la articulación de la cooperación penal internacional" (Badia Martí, 2008, p. 320).

Esta investigación tiene como marco teórico la dogmática penal en torno a los delitos internacionales desarrollada principalmente por Kai Ambos, y cuya aplicación en México se particulariza para el delito de tráfico de drogas, sin que eso signifique que no existan otras conductas, además de la de traficar, que merezcan ser tipificadas como delitos internacionales.

\section{METODOLOGÍA}

El desarrollo de este trabajo de investigación tiene como base el método hipotético deductivo pues se parte de un análisis general de los delitos internacionales y su desarrollo en el Estatuto de Roma para posteriormente enfocarlo al delito de tráfico de drogas en México.

Se utilizó una base documental internacional y nacional que buscó definir ciertos parámetros a partir de los cuales el delito de tráfico de drogas, que generalmente es de tipificación nacional, puede ser considerado como delito internacional, así, metodológicamente se partió de la palabra tráfico que es definida por el diccionario jurídico de la Real Academia Española (en adelante RAE) como "tránsito o circulación de vehículos, personas y animales por las vías y terrenos de utilización general" (RAE: web); es decir, la conducta tiene que ver con la circulación que hacen las personas de drogas entre dos o más países.

Inclusive el diccionario jurídico de la RAE al referirse a la frase "tráfico de drogas", la conceptualiza como la "actividad que consiste en la transmisión de drogas" (RAE: web); y de igual manera, cuando conceptualiza lo referido al "delito de tráfico de drogas", lo define como "delito que consiste en comerciar con drogas tóxicas, estupefacientes o sustancias psicotrópicas" (RAE: web). Por lo tanto, la palabra "tráfico" trae implícita la realización de dos fines de la conducta, los cuales son: a) transportar que puede ser al interior (delito nacional tipificado así por los Códigos Penales Nacionales), o internacional (transporte que trasciende las fronteras nacionales de dos o más Estados y en cuyo caso será delito internacional, que no se encuentra tipificado como tal por los instrumentos internacionales pero que puede ser considerado como un delito de lesa humanidad, y por lo tanto, ser tipificado de manera indirecta como delito internacional); y b) comerciar, es decir, la obtención de una ganancia o lucro con motivo del transporte de una mercancía (que en este caso será la droga). 
Y por lo que respecta a la palabra "droga", en términos señalados por el diccionario jurídico de la RAE se entiende como "droga tóxica, estupefaciente o sustancia psicotrópica (RAE: web); por lo tanto, para ampliar el contenido de esta palabra, metodológicamente se adopta lo señalado por los artículos 193 del Código Penal Federal mexicano (en adelante CPF), en relación con lo señalado por los artículos 237, 245 fracciones I, II y III, y 248 de la Ley General de Salud de México (en adelante LGS), cuyo numeral 237 establece que se entiende por droga "opio preparado, para fumar, diacetilmorfina o heroína, sus sales o preparados, papaver somniferum o adormidera, papaver bactreatum y erythroxilon novogratense o coca, en cualquiera de sus formas, derivados o preparaciones"; cabe mencionar que las sustancias psicotrópicas se establecen en las fracciones I, II y III del artículo 245 del CPF todo ello en el marco de los tratados internacionales como el CNUCTIESP.

Desde el punto de vista metodológico, el planteamiento de este objeto de investigación permite concluir válidamente una hipótesis predictiva, en el sentido de que por los efectos de la globalización, las fronteras nacionales ya no representarán un obstáculo para la realización de determinadas actividades, incluyendo aquellas de índole criminal, como el tráfico de drogas, por lo tanto, el poder punitivo del Estado deberá ser cooperativo con instancias supranacionales como la Corte Penal Internacional (en adelante CPI) para la persecución de aquellas conductas criminales, que por su propia naturaleza, rebasen la capacidad técnica y operativa de un Estado para hacerles frente.

\section{EL DELITO INTERNACIONAL COMO DISCUSIÓN TEÓRICA}

Previamente a señalar una definición de delito internacional, es necesario puntualizar que los delitos internacionales no son fáciles de delimitar porque generalmente ocurren a una escala masiva, en un lapso prolongado, e incluye diferentes delincuentes en varios niveles de mando y resultan en cantidades copiosas de víctimas $^{1}$ (Fry, 2015, p. 163). No es suficiente que una determinada conducta sea considerada como delito internacional, sino que su comprobación

1. La traducción es propia y la cita textual es: "international crimes are not easy to demarcate [...] generally occur on a massive scale over a prolonged period of time involving many different perpetrators at various levels of command and resulting in copious amounts of victims". debe ser posible, estableciendo de la forma más detallada posible, los elementos del tipo penal internacional que posibilite a los tribunales, la determinación de las 5 " $W$ ", que por sus siglas en inglés significan: a) Who, es decir, quién o quienes cometen el delito; b) What; qué delito; c) When; cuándo ocurrió el delito; d) Where; dónde ocurrió la conducta criminal; y e) Why; por qué se cometió esa conducta (Fry, 2015, pp. 165-166).

Existen diferentes conceptos de delito internacional; por ejemplo, se denomina como delito internacional a aquella conducta criminal en la que aparece un elemento extranjero. Para Kelsen, delito internacional son aquellas "violaciones del derecho internacional" (2011, p. 324). Además, teóricamente, esta investigación parte de lo que por delito internacional ha desarrollado Ambos quien señala que:

el concepto de delito en Derecho Penal Internacional es producto de la jurisprudencia penal internacional desde Nuremberg y de las codificaciones internacionales $y$ no una consecuencia lógica o racional del desarrollo de la teoría del delito a lo largo de los siglos [...] en el Derecho Penal Internacional se presenta una estructura bipartita del delito que diferencia por un lado actus reus y mens rea, y por otro, entre la responsabilidad individual (con fundamento en una offence) y las posibles causas de exclusión de la punibilidad (defenses) (2010, p. 35).

De lo anterior se desprende que la dogmática penal internacional se encuentra en un proceso de creación y consolidación, de tal manera que son los propios tratados internacionales, acordados por la comunidad global, los que tipifican una conducta como delito; por lo tanto,

en el ámbito del Derecho Penal Internacional está todavía por desarrollar una teoría del tipo penal [...] Del mismo modo, la comprensión del tipo como tipo sistemático (Systemtatbestand) basado en la idea fundamental de la descripción precisa del injusto material puede servir para contribuir a la precisión de los tipos delictivos del Derecho Penal Internacional (Ambos, 2010, p. 36).

En el ámbito internacional "existe un sistema causalista clásico del delito el cual gira en torno a dos cuestiones: ¿infringe una persona con su conducta una norma? (de Derecho Penal Internacional) y irealiza con esto un injusto? 
(de Derecho Penal Internacional)" (Ambos, 2010, p. 131). Para resolver ambas preguntas problematizadoras se recurre al Derecho Internacional en su vertiente penal, dado que se tiene implícito un acuerdo de voluntades por los Estados para considerar a una conducta como delictuosa, sea que dicha conducta se encuentre directamente establecida en un tratado internacional, o bien, que sea éste el que obligue a los Estados a adoptar legislación interna penal que sancione conductas que previamente hayan sido catalogadas como criminales en el ámbito internacional. En el primer caso, estaremos en presencia de una tipificación internacional directa; y en el segundo caso, de una tipificación internacional indirecta. Por otro lado, es conveniente resaltar que a este tipo de conductas criminales, se les ha venido denominando como infracciones internacionales, según refiere Badía Martí, en relación a la protección de determinados bienes jurídicos, y que básicamente se clasificaron en cuatro tipo de bienes a proteger, ellos son:

a) Protección del bien jurídico relacionado con el individuo y los pueblos. En este se incluyen aquellas conductas como la trata de personas, la tortura, la discriminación racial, las desapariciones forzadas, entre otras.

b) Protección del bien jurídico relacionado con los sujetos de derecho internacional, es decir, los Estados y las Organizaciones Internacionales. En este se incluyen conductas criminales como la falsificación de moneda, la corrupción, el terrorismo, atentados contra embajadas y demás representaciones diplomáticas, etc.

c) Protección del medio ambiente como la contaminación deliberada, y en general, la destrucción de los espacios abiertos, es decir, aquellos que pertenecen a toda la humanidad.

d) Protección del comercio internacional, como pueden ser aquellas conductas que trafican con bienes culturales, la pornografía en todas sus vertientes, tráfico de estupefacientes, piratería informática, delitos cibernéticos, etc. (2008, p. 332).

Cada uno de estos bienes jurídicos tutelados, responde a una conducta diferente que obviamente se atribuye a un sujeto en particular. Por ejemplo, alguien contamina deliberadamente, alguien hace explotar una bomba en una embajada, alguien trafica drogas, etc., la diferencia es que, según Shünemann, en el "Derecho Penal Internacional la imputación sólo puede ser entendida en un sentido amplio y también no específico como la relación entre el sujeto de la acción y el resultado, debiéndose imputar en primer lugar la acción a la persona y luego el resultado a la acción" (citado por Ambos, 2005, p. 147). Así, primero se determina la acción (tráfico de drogas) y luego, el sujeto (Juan "N" líder del Cartel del Golfo); y posteriormente, se relaciona el resultado (tráfico de drogas de México hacia Estados Unidos) con la acción del sujeto (Juan "N" trafica drogas de México hacia Estados Unidos). De esta última relación dependerá el carácter internacional, toda vez que, en el mismo ejemplo, pueda haber una acción (tráfico de drogas), atribuible a una persona (Juan "N"), pero cuyo resultado sea solamente al interior del Estado, en cuyo caso, será éste el que tendrá la competencia para perseguir y sancionar una conducta criminal.

No se pierde de vista que habrá delitos que por su alcance sean tipificados en un tratado internacional, y que por esta circunstancia, sean considerados como internacionales (delitos internacionales strictu sensu); sin embargo, en este mismo caso, previamente se consideró que el resultado relacionado con la acción tiene un alcance internacional, y consecuentemente, tiene esta misma naturaleza.

Así, el objetivo del Derecho Penal Internacional según Jäger, citado por Ambos, sería "identificar y hacer visible la responsabilidad individual" (2005, p. 154), partiendo, de acuerdo con Marxen, de "un sistema de principios axiomáticos reconocidos para la comprensión conceptual del delito de derecho internacional" (citado por Ambos, 2005, p. 159). Cabe mencionar que un principio axiomático que de alguna manera sentó las bases para considerar una conducta como delito internacional fue el principio jus cogens, o norma imperativa de derecho internacional general, reconocido por la Convención de Viena sobre el Derecho de los Tratados en su artículo 53 que a la letra dice:

"una norma imperativa de derecho internacional general es una norma aceptada y reconocida por la comunidad internacional de Estados en su conjunto como norma que no admite acuerdo en contrario y que sólo puede ser modificada por una norma ulterior de derecho internacional general que tenga el mismo carácter" (CVSDT: web). 
Es decir, si una vez reconocida una norma imperativa como tal en el ámbito internacional, es vulnerada, entonces existe un delito internacional porque al haber sido aceptada y reconocida internacionalmente, el resultado añadido a una conducta tiene alcances internacionales. Por ejemplo, la prohibición del tráfico de drogas es una norma imperativa, si se vulnera, se comete un delito. Igualmente, la prohibición de la piratería, es una norma imperativa de derecho internacional general, si se vulnera, se comete un delito.

Dentro de este concepto de normas jus cogens, caben todas aquellas que tengan el carácter de prohibitivas internacionalmente, por ende, si se vulneran, tienen el carácter de delito internacional, al haber sido aceptadas y reconocidas por la comunidad internacional, como normas no sólo de impacto global, sino además, de normas necesarias para la convivencia entre los sujetos de derecho internacional.

Dice Marxen que para que una conducta sea considerada como delito internacional debe reunir dos características: gravedad y estructura, lo que traería como consecuencia dos problemas. Por un lado, la conducta debe ser grave, es decir, no cualquier conducta debe ser considerada como delito internacional sino sólo aquella en la que la actividad punitiva del Estado no sea suficiente; además, la conducta debe ser estructurada, es decir, determinada como delito a través de la creación de los tipos penales; la creación de un concepto material del delito internacional (citado por Ambos, 2005, p. 159).

En el ámbito internacional no está claro si un régimen supranacional penal está orientado principalmente a proveer un marco para los Estados de asistencia recíproca para alcanzar los objetivos nacionales de justicia, mediante la creación de una agenda "entre naciones", o, en su lugar, significa primariamente, reflejar y promover normas de justicia global, una agenda de justicia "global"2 (De Guzman, 2016, p. 178).

Y ello se debe a que, generalmente el derecho penal fue pensado para aplicarse al interior de los

2. La traducción es propia y la cita textual es: it remains unclear whether the supranational criminal law regime is intended largely to provide a framework for states to assist one another in effectuating national justice goals, an "inter-national justice agenda, or is instead meant primarily to reflect and promote global justice norms, a "global" justice agenda.
Estados, es decir, como un producto cultural en términos de Häberle, es decir, como "la expresión de un cierto grado de desarrollo cultural" (2000, p. 34); no obstante, la globalización del derecho, demanda una nueva forma de ver al derecho penal, no sólo como aquél que tiene validez jurídica al interior del Estado, sino fuera de él, en un concepto de espacios abiertos en donde el derecho también cumple un papel regulador, ya sea definiendo, mediante tratados internacionales, aquellas conductas que son consideradas como delictivas, creando una instancia supranacional con competencia para conocer de dichas infracciones penales, o bien, mediante la creación de mecanismos de cooperación jurídica internacional para aquellas conductas que por su naturaleza puedan transgredir normas internas de dos o más naciones; sin olvidar aquel derecho penal en donde el sujeto activo del delito es de nacionalidad extranjera, que aunque es procesado, juzgado y sentenciado conforme a las leyes nacionales de donde cometió el delito, también es internacional dada su nacionalidad.

\section{EL CARÁCTER DE DELITO INTERNACIONAL DEL TRÁFICO DE DROGAS}

Los Estados y las organizaciones internacionales han venido realizando esfuerzos para detectar aquellas conductas que por su naturaleza puedan tener un impacto internacional, por lo tanto, buscan que se incorporen al campo del derecho mediante la creación de tipos delictivos que planteen una estrategia común frente a una realidad que no es suficiente atenderla con la legislación exclusiva de un solo Estado. Por ello es que, "el marco regulatorio del sistema internacional de fiscalización de drogas se compone principalmente por la Convención Única sobre Estupefacientes (enmendada por el Protocolo de 1972), el Convenio sobre Sustancias Sicotrópicas de 1971 y la Convención de las Naciones Unidas contra el Tráfico Ilícito de Estupefacientes y Sustancias Sicotrópicas de 1988" (Cuenca Curbelo, 2013, p. 107).

La gran mayoría de estas conductas delictivas transnacionales son realizadas por grupos perfectamente organizados y estructurados, que en el campo del estudio del derecho internacional penal, son conductas propias de la delincuencia organizada trasnacional, en donde, cada vez se añaden nuevos tipos penales internacionales a los ya existentes. 
La incorporación de nuevos tipos penales internacionales se debe a que la sociedad internacional lo que busca es un "plan de acción Mundial contra la delincuencia transnacional organizada que se formula con el objetivo de sentar las bases de una acción mundial, concertada y eficaz" (Badía Martí, 2009, p. 339). Ello con la finalidad de establecer una estructura normativa internacional que establezca un frente de acción jurídica en el ámbito penal para aquellos "grupos que cuentan con una estructura compleja para crear, sostener y explotar mercados de bienes (drogas) y servicios ilegales con el fin de obtener beneficios económicos" (Guerrero Agripino, 2012, p. 68).

$\mathrm{Y}$ es en esta tendencia de incorporar un mayor número de conductas que pueden ser considerados como delitos internacionales en donde se incorpora la propuesta de este trabajo de investigación, de incorporar al delito de tráfico de drogas como internacional dentro del parámetro señalado en el artículo 5 del Estatuto de Roma, en cuyo párrafo primero inciso b), se hace referencia a los crímenes de lesa humanidad, pues señala textualmente:

Artículo 5. Crímenes de la competencia de la Corte. 1. La competencia de la Corte se limitará a los crímenes más graves de trascendencia para la comunidad internacional en su conjunto. La Corte tendrá competencia [...] b) Los crímenes de lesa humanidad.

Posteriormente, el Estatuto de Roma conceptualiza a estos delitos internacionales en el artículo 7, párrafo primero (inciso k), señalando:

Artículo 7. Crímenes de lesa humanidad. 1. A los efectos del presente Estatuto, se entenderá por "crimen de lesa humanidad" cualquiera de los actos siguientes cuando se cometa como parte de un ataque generalizado o sistemático contra una población civil [...] k) Otros actos inhumanos de carácter similar que causen intencionalmente grandes sufrimientos o atenten gravemente contra la integridad física o la salud mental o física.

Pues bien, en los términos antes mencionados por el Estatuto, es claro que no cualquier tipo de conducta criminal debe ser de la competencia de la CPI, sino sólo aquellas conductas graves que atenten contra la comunidad internacional en su conjunto, y que además, sean cometidas de manera generalizada y sistemática, con la clara intención de atentar contra la salud mental y física de las personas; todas estas características del tipo penal de lesa humanidad las tiene el de tráfico de drogas, porque su comisión afecta a toda la comunidad internacional, es decir, "existe una extensión casi universal en el consumo de drogas" (Guerrero Agripino, 2012, p. 213), y lo hace en su salud física y mental, pues de todos son conocidos los efectos que causa su consumo en la salud, y atendiendo al principio de que lo evidente no se prueba, esta propuesta se funda en las graves consecuencias que se causan a la salud de las personas. Además, por tratarse de un delito cuya comisión es transnacional, porque van implícitos dos o más Estados (el del lugar de su producción y el del lugar de su consumo, cuando menos), su conocimiento puede ser de la competencia de la Corte; máxime si consideramos que el tráfico de drogas es realizado por la delincuencia organizada que muchas veces supera en recursos logísticos, económicos y de armamento al que tienen los Estados.

De lo anterior se desprende que ésta propuesta también encuentra sustento en lo señalado por el artículo 2 de la CNUCDOT; que establece textualmente:

Artículo 2. Definiciones. Para los efectos de la presente Convención: [...] b) Por "delito grave" se entenderá la conducta que constituya un delito punible con una privación de libertad máxima de al menos cuatro años o con una pena más grave (CNUCDOT: web).

Por ende, entratandose de delitos graves, será aplicable este instrumento internacional, sin embargo, la CNUCDOT no establece expresamente cuales son esos delitos graves, dado que la convención sólo se refiere a cuatro tipos penales señalados en los artículos 5, 6, 8 y 23 de la propia Convención, mismos que se refieren a: a) participación en un grupo delictivo organizado; b) blanqueo del producto del delito; c) corrupción; y d) obstrucción de la justicia. Lo que significa que el delito de tráfico de drogas, por ser grave, pueda ser considerado también como delito trasnacional, siempre y cuando se cumplan con los requisitos marcados en el segundo párrafo del artículo 3 de la CNUCDOT que textualmente señala:

Artículo 3. Ámbito de aplicación. [...] 2. A los efectos del párrafo 1 del presente artículo, el delito será de carácter transnacional si:

a) Se comete en más de un Estado; 
b) Se comete dentro de un solo Estado pero una parte sustancial de su preparación, planificación, dirección o control se realizan en otro Estado;

c)Se comete dentro de un solo Estado pero entraña la participación de un grupo delictivo organizado que realiza actividades delictivas en más de un Estado; o

d) Se comete en un sólo Estado pero tiene efectos sustanciales en otro Estado.

En principio, por las características del delito de tráfico de drogas, se puede conceptualizar tanto delito transnacional como internacional, que para efectos de esta investigación ambos conceptos entrarían dentro de la dogmática penal de delito internacional de Kai Ambos; pues bien, cuando se profundiza en el estudio de este delito en cuanto a los mecanismos de los que disponen los Estados para hacerle frente a este flagelo social, se concluye que en principio se trata de un delito nacional que se transforma en trasnacional al trascender las fronteras nacionales, toda vez que su persecución y sanción le compete a cada uno de los Estados en donde el delito se genere o produzca sus resultados; consecuentemente, las actividades de procuración e impartición de justicia seguirán siendo preponderantemente nacionales, además de que, en estricto sentido cuando se trata de delitos transnacionales, se carece de una autoridad transnacional o supranacional que realice estas funciones de procuración e impartición de justicia, mientras que si es un delito considerado como internacional, será la CPI la que tenga jurisdicción.

Así se ha reconocido en la CNUCDOT, ya que conforme lo señalado por los artículos 11 y 15, "Cada Estado Parte penalizará la comisión de los delitos tipificados con arreglo a los artículos 5, 6, 8 y 23 de la presente Convención con sanciones que tengan en cuenta la gravedad de esos delitos" y "adoptará las medidas necesarias para establecer su jurisdicción respecto de los delitos tipificados con arreglo a los artículo 5, 6, 8 y 23 de la presente Convención" (CNUCDOT: web); numerales que tipifican los delitos a los que ya se hizo referencia en supralíneas; pues bien, suponiendo que se incorporase como delito transnacional al tráfico de drogas, le correspondería a la autoridad mexicana sancionar este delito, lo que ya se hace, y consecuentemente, no existiría ninguna aportación al conocimiento, pues ya se considera al delito de tráfico de drogas como transnacional cuando reúne los requisitos marcados por el artículo 3 de la CNUCDOT, por ello es que la aportación, sería en el sentido de considerarlo como internacional, particularmente, se propone su consideración como delito de lesa humanidad al afectar gravemente la salud física y mental de las personas de distintos Estados, y por lo tanto, atribuirle a la CPI la competencia en cuanto a su persecución y sanción. Es decir, la aportación de esta investigación es atribuirle al delito de tráfico de drogas uno de los elementos faltantes, y que es el que corresponde a la estructura. Y esta estructura sería satisfecha al ser incorporado como delito de lesa humanidad.

Por supuesto que no todos los delitos relacionados con el tráfico de drogas serían de la competencia de la CPI, sino sólo aquellos verdaderamente graves, considerados así por diversos elementos entre los que destacaría, por ejemplo, la peligrosidad del probable delincuente $\mathrm{y}$ los efectos de su actividad delincuencial. De tal manera que la competencia de este tribunal internacional no suplantaría a la que ya tienen las autoridades nacionales, sino que la complementaría, y en la práctica equivaldría a extraditar al delincuente, no para que sea procesado y sentenciado por el tribunal nacional de otro Estado (lo que es plenamente posible conforme a las disposiciones de la CNUCDOT); sino para que sea procesado y sentenciado por un tribunal internacional, con la plena colaboración de las autoridades nacionales.

Y esta aportación es particularmente importante porque ya se ha pensado incorporar al delito de tráfico de drogas como internacional, pero "por falta de consenso, ni terrorismo, ni el tráfico de sustancias alucinógenas, quedaron tipificados como crímenes en el Estatuto de Roma, siendo dos fenómenos completamente desestabilizadores en la actualidad" (Mejía Azuero, 2008, p. 192).

\section{EL TRÁFICO DE DROGAS EN LA LEGISLACIÓN MEXICANA}

El tráfico de drogas en México es uno de los principales delitos que aquejan a la población, a pesar de que pudiera considerarse que es sólo un país productor y exportador, más no consumidor, o cuando mucho, sería considerado como un país consumidor en menor escala, en comparación con los altos niveles de consumo de narcóticos, principalmente mariguana, existentes en América del Norte (Estados Unidos y Canadá) y Europa, según datos establecidos en el Reporte Anual 
2018 sobre Demanda y Consumo de Drogas realizado por la Oficina de las Naciones Unidas para las Drogas y Crimen (UNODOC: web).

Sin embargo, es un delito importante ya que es principalmente realizado por la delincuencia organizada que

constituye uno de los problemas más graves que el Estado Mexicano enfrenta actualmente, tanto por la magnitud de la violencia ejercida en el desarrollo de sus actividades (v.g. tráfico de drogas) y la frecuencia con la que ésta se realiza, como por la desestructuración social (Guerrero Agripino, 2011, p. 2).

De tal manera que aunque el delito de tráfico de drogas esté codificado nacionalmente en México, al considerarse como delito del orden federal, al ser realizado por la delincuencia organizada, su comisión adquiere elementos internacionales, por ende, susceptible de ser considerado también como un delito internacional en los términos que se han venido desarrollando a lo largo de este trabajo de investigación, esto es así porque como toda conducta humana, la "delincuencia se sitúa en contextos específicos y en circunstancias particulares, además evoluciona constantemente. Esto, sin duda alguna, ha sido provocado por la globalización" (Guerrero Agripino, 2011, p. 4). De tal suerte que si la comisión de un delito es hecha por un grupo delincuencial organizado, deja de ser nacional, para convertirse también en internacional, sobre todo porque los resultados de su comisión (tráfico de drogas) trasciende fronteras, en una concepción clara de globalización de la criminalidad, o en términos de Ferrajoli, "uno de los efectos perversos de la globalización es sin duda el desarrollo, con dimensiones globales que no tienen precedente, de una criminalidad internacional, a su vez global" (2006, p. 301).

Es en esta postura de Ferrajoli en donde se encuentra epistemológicamente situada esta investigación, pues en la actualidad países como México, se enfrentan a una "incapacidad para producir reglas a la altura de los nuevos desafíos abiertos por la globalización" (Ferrajoli, 2006, p. 302), pero además, la propia globalización le plantea un nuevo paradigma al derecho penal que se plantea en forma de pregunta de investigación: ¿Cómo hacerle frente al delito de tráfico de drogas, cuya comisión trasciende las fronteras del Estado mexicano?, cuestión que se relaciona con las preguntas planteadas en la parte introductoria cuando se definió el objeto de esta investigación.

La hipótesis es tipificar al delito de tráfico de drogas como internacional, teniendo como marco de referencia el caso mexicano, para que exista una competencia concurrente entre las autoridades nacionales y la CPI para perseguir y sancionar esta conducta, pues en la actualidad, la mejor forma de enfrentar a la criminalidad internacional "ha sido mediante la creación de la Corte Penal Internacional para los crímenes contra la humanidad" (Ferrajoli, 2006: 307); es por ello, que la propuesta es la consideración del delito de tráfico de drogas como de lesa humanidad.

En el caso mexicano, el delito de tráfico de drogas se encuentra regulado por los artículos 193 y 194 que se encuentran en el título séptimo referido a delitos contra la salud del Código Penal Federal; y particularmente, el capítulo primero se refiere al tráfico de drogas, mismo que en el artículo 193 se refiere a lo que debe entenderse por "droga", lo cual fue explicado en la parte metodológica en donde se expuso el planteamiento inicial de esta propuesta; mientras que en el numeral 194 fracción I se establece que se impondrá una pena de 10 a 25 años de prisión a quien trafique drogas (por lo tanto es un delito grave en los términos señalado por la CNUCDOT al exceder los 4 años).

Por otra parte, la palabra "tráfico" conforme al diccionario jurídico de la RAE, trae aparejadas las conductas de "transporte" y "comercio", que a su vez implica "vender, comprar, adquirir o enajenar" acciones que también están especificadas en la fracción I del artículo 194 del CPF.

Además, la palabra "tráfico", tal y como fue señalado en la parte metodológica trae aparejada la acción de "posesión", conducta que en materia de drogas, estupefacientes y psicotrópicos en términos de la Ley General de Salud (en adelante LGS) también está prohibida por el artículo 195 del CPF, sólo que con una penalidad menor, ya que ésta oscila entre los 5 y 15 años.

Como se puede desprender de los anterior, el traficar drogas implica: poseer, transportar, comerciar, vender, comprar, adquirir, y/o enajenar drogas (estupefacientes y psicotrópicos prohibidos), lo que implica que el empleo de la palabra "trafico", trae como resultado la actualización de cuando menos 7 tipos de 
conductas diferentes que pueden ser consideradas como delitos internacionales.

De todo el análisis del CPF en ningún momento se señala algo que pudiere traer como consecuencia la idea de que el tráfico de drogas también puede ser un delito internacional, por ende, resulta importante el sentido de esta aportación académica de que al menos, los códigos penales nacionales señalaren que cuando se este delito trascienda las fronteras nacionales, pueda ser considerado como internacional conforme a los tratados internacionales de los que cada Estado sea parte.

\section{LA PROBLEMÁTICA DEL PRINCIPIO NON BIS IN ÍDEM EN EL CASO DEL DELITO DE TRÁFICO DE DROGAS}

La hipótesis de esta investigación se centra en la naturaleza internacional, además de nacional, que tiene el delito de tráfico de drogas, que conforme fue señalado en líneas arriba, es conceptualizado como un crimen por la legislación nacional mexicana y se propone que se considere como un delito internacional de lesa humanidad conforme al Estatuto de Roma, para hacer efectiva la competencia, caso por caso (case by case), que ya tiene la CPI en México; consecuentemente, resulta importante definir cual de los dos tribunales, el nacional o internacional, tendrá competencia para conocer y resolver un caso de tráfico de drogas, a la luz del principio non bis in ídem.

Ello resulta importante puesto que en la era de la globalización jurídica, las personas individuales pueden ser responsable conforme al derecho penal estatal en tribunales nacionales, o bien, ante cortes o tribunales internacionales en caso de delitos internacionales por ciertas flagrantes y sistemáticas violaciones de relevancia para los parámetros internacionales ${ }^{3}$ (Brus, 2015, p. 360).

Pues bien, este principio es encontrado en casi todos los sistemas nacionales, regionales o internacionales del mundo. Significa literalmente "no dos veces por lo mismo". Los detalles del principio varían por sistema, pero en la mayoría de los sistemas nacionales "lo mismo" implica una

3. La traducción es propia y la cita textual es: Individuals [...] also can be held liable under international criminal law in domestic courts or before international courts and tribunals for certain gross and systematic violations of relevant international standards. aproximación en los hechos (los hechos históricos y conducta) en oposición a la aproximación legal (un delito en particular que ofrece una protección más estrecha) ${ }^{4}$ (Fry, 2015, pp. 208-209).

Por lo tanto, en la determinación del tribunal competente para conocer del delito de tráfico de drogas, será muy importante la gravedad del resultado de la acción delictiva, aunque por la propia naturaleza de este tipo de delitos, sus alcances generalmente son internacionales, pues como ya se señaló previamente, estos delitos se caracterizan por producirse en una escala masiva cuya delimitación territorial es difícil, y cuyas víctimas son muchas.

Al tener el delito de tráfico de drogas una tipificación nacional, y cuando sus resultados o alcances sean dentro de las fronteras nacionales, la competencia punitiva será exclusivamente del Estado nacional. Pero cuando el delito tenga una tipificación internacional y se le considere como delito de lesa humanidad, los tribunales internos e internacionales (CPI) tendrán una relación en términos de cooperación jurídica, y esta puede ser vertical u horizontal, de ahí que se le conozca como una "trans-jurisdicción". En el plano vertical, la relación entre tribunales se da de abajo hacia arriba y de arriba hacia abajo; pues se trata de dos tribunales con diferente jurisdicción; sea que la nacional empuje a la internacional o viceversa; mientras que en el plano horizontal, la jurisdicción es interna, ya sea que sólo sea al interior de un tribunal nacional o al interior de un tribunal internacional (Fry, 2015, p. 209).

En ambos casos, la jurisdicción se definirá de acuerdo a los alcances del delito, si éstos son exclusivamente nacionales o exclusivamente internacionales, será una jurisdicción horizontal; mientras que si un delito se comete en el interior de un Estado pero los resultados a afectan a otros, la jurisdicción será vertical. Cuando sea definido un delito como internacional en este ámbito, es difícil que se delegue la jurisdicción a un tribunal nacional, porque es precisamente el tratado internacional el que tipifica una conducta como

4. La traducción es propia y la cita textual es: It is a principle found in nearly every system -national, regional and international- in the world. Ne bis in ídem literally means "not twice for the same". The principle's details vary per system, but in most national systems "the same" entails factual approach (the historical facts and conduct) as opposed to a legal approach (a particular criminal offense, which offers narrower protection. 
delito internacional. Sea la jurisdicción vertical u horizontal, la cooperación jurídica tendrá que considerar el principio de non bis in ídem para no someter a proceso la misma conducta ante diferentes tribunales, ya sea otro tribunal nacional, o bien, un tribunal internacional, tomando en consideración la aproximación legal, es decir, lo que el tipo penal nacional o internacional establezcan, con independencia de la consideración fáctica de los hechos.

Además, para efecto de fijar la jurisdicción que habrá de conocer del delito de tráfico de drogas, existen cuatro criterios que se han utilizado; el primero es el que se basa en el principio de territorialidad que implica que tendrá jurisdicción el Estado en el que se cometió el delito; el segundo es el que se conoce como el principio de nacionalidad activa, que significa que será competente para conocer del delito el Estado de la nacionalidad del probable responsable; el tercer criterio es el que utiliza como base el principio de nacionalidad pasiva que significa que tendrá jurisdicción el Estado de la nacionalidad de la víctima; y finalmente, lo que se conoce como el principio de protección que permite que los Estados en donde sus intereses esenciales se han puesto en riesgo por un acto cometido fuera de su jurisdicción, puede ejercer su jurisdicción ${ }^{5}$ (Brus, 2014, p. 365); sin olvidar que existe propiamente el principio de jurisdicción internacional que puede ser ejercitada por los tribunales o cortes internacionales cuando el delito afecta a toda la comunidad global, y que puede ser ejercida cuando la conducta se encuentra tipificada como delito en un tratado internacional, pues existen conductas criminales que se reprimen globalmente y representan una forma de responder a una idea de justicia universal $o$ de jurisdicción universal para delitos como: piratería, genocidio, crímenes en contra de la humanidad, entre otros; que hipotéticamente no sólo permitiría el ejercicio de la jurisdicción por

5. La traducción es propia y la cita textual de la que se tomó es la siguiente: International law it is generally accepted that domestic criminal jurisdiction can be base don the territoriality principle, the active and passive nationality principle, and the protective principle. The first entitles the state in which the crime was committed to exercise jurisdiction, the active principle entitles the state of the nationality if the accused to exercise jurisdiction, the passive principle -subject to various qualifications- entitles the state of nationality of the victim to exercise jurisdiction and the protective principle allows the states whose essential interests have been jeopardized by an act committed outside the forum state to exercise jurisdiction. un tribunal o corte internacional; sino además, cualquier Estado tendría la posibilidad de hacerlo.

\section{LA ACEPTACIÓN DE LA JURISDICCIÓN DE LA CORTE PENAL INTERNACIONAL POR MÉXICO}

Una de las instituciones internacionales que surgieron para perseguir y sancionar un delito internacional es la CPI, la cual nace con la idea de actuar en beneficio de la comunidad global; aunque su legitimidad es precaria para aquellas acciones que afectan a los Estados que no han consentido o aceptado su jurisdicción ${ }^{6}$ (De Guzman, 2016, p. 179). Surgió como una necesidad imperativa de tener una institución capaz de impartir justicia en una forma global, más allá de los límites impuestos por las fronteras de las naciones ${ }^{7}$ (Scheider et al; 2014, p. 1). La jurisdicción de la CPI es complementaria y subsidiaria a la jurisdicción nacional, ya que en los términos señalados por el artículo 17 del Estatuto de Roma "se respeta la posibilidad del Estado para conocer y resolver su conflicto soberanamente, y sólo en caso de que los procesos penales resultaran ineficaces o imposibles de instaurar se presenta la posibilidad de actuación de la Corte" (Kala y Martínez, 2011, p. 27).

La CPI tuvo como antecedentes dos tribunales internacionales penales que surgieron al término de la Segunda Guerra Mundial con el propósito de sancionar a los responsables de las atrocidades causadas; ellos fueron el Tribunal Internacional Militar de Nürenberg, y el Tribunal Internacional Militar de Tokio; también tuvo como antecedentes otros dos tribunales internacionales que aparecieron en los años noventa del siglo pasado, y que eran muy parecidos a los de Nüremberg y Tokio, los cuales fueron el Tribunal Penal Internacional para la Antigua Yugoslavia y el Tribunal Internacional de Ruanda. Algo que caracterizó a todos estos tribunales penales internacionales fue que respondieron a una situación en particular, es decir, su nacimiento fue una reacción a lo que sucedía en la realidad, lejos de pensarse en su creación permanente de forma institucional y con la cooperación de todos los Estados.

6. La traducción es propia y la cita textual es: If institutions such as the ICC cannot claim to act on behalf of a global community, their legitimacy becomes precarious, particularly when their actions affect states that have not consented to their authority.

7. La traducción es propia y la cita textual es: the imperative need of official institutions capable of doing justice in a global way, beyond the limits imposed by borders of the nations. 
Con estos antecedentes nace la CPI, conformada actualmente por 123 Estados miembros, con sede en La Haya, Holanda, y cuya competencia sólo podrá ser ejercida sobre los asuntos de los Estados, que previamente hayan reconocido o consentido su jurisdicción, conforme a los intereses nacionales que en cada nación se persigan. Existen casos, como el de México, que aceptó esa jurisdicción internacional, después de haber adicionado el artículo 21 de la Constitución Política de los Estados Unidos Mexicanos (en adelante CPEUM), que textualmente señala: "Artículo 21.- [...] El Ejecutivo Federal podrá, con la aprobación del Senado en cada caso, reconocer la jurisdicción de la Corte Penal Internacional"; adición que fue publicada en el Diario Oficial de la Federación el 20 de junio del 2005; curiosamente, un día antes de que la Cámara de Senadores aprobara el Estatuto de Roma de la CPI el 21 de junio del 2005.

Ello demuestra, la afirmación que Hans Kelsen desarrollara en su teoría pura del derecho al señalar que "el derecho internacional [...] es derecho en el mismo sentido que el derecho estatal, $y$, por ende, si en general puede ser objeto de una ciencia jurídica" (2011, p. 323). Toda vez que a la par que se aprueba por el Senado, el tratado internacional conocido como Estatuto de Roma, al mismo tiempo se adiciona el texto constitucional mexicano en su artículo 21, para darle plena vigencia al referido instrumento internacional al reconocer la jurisdicción de la CPI.

Además, conforme al decreto de promulgación del Estatuto de Roma que establece la CPI, desde el 7 de septiembre del año 2000 se firmó por parte del Ministro Plenipotenciario del Gobierno Mexicano este instrumento internacional, dicha firma fue ad referéndum, es decir, se trató de una firma provisional que requería de una posterior ratificación por parte del titular del Poder Ejecutivo Federal, y que en términos jurídicos, significa la expresión de la voluntad por parte del Gobierno Mexicano en obligarse por ese tratado en los términos señalados por el artículo 11 y 12 de la Convención de Viena Sobre el Derecho de los Tratados (en adelante CVSDT).

Consecuentemente, si atendemos la cronología marcada tanto por el decreto a través del cual se modifica el artículo 21 de la Carta Magna Mexicana y el que promulga el Estatuto de Roma, se tiene que desde el 7 de septiembre del año 2000, el Gobierno de los Estados Unidos Mexicanos, a través de su
Ministro Plenipotenciario expresó, ad referéndum, su consentimiento en obligarse por este tratado internacional, $\mathrm{y}$ consecuentemente, reconocer la jurisdicción de la CPI, sin embargo, debido a que el texto de la CPEUM no señalaba nada al respecto, se esperó hasta un día después de la modificación a la Carta Magna mexicana, es decir, el día 21de junio del año 2005 para que el Senado de la República, en los términos marcados por el artículo 76 fracción I de la Carta Magna mexicana aprobara dicho tratado internacional, una vez que ya había sido subsanada la omisión en el texto constitucional; lo anterior demuestra la influencia del derecho internacional sobre el derecho interno, y la modificación de éste último en términos de lo señalado por el primero, comprobando, al menos en lo que a este aspecto de aceptación de la jurisdicción de la CPI se refiere, la unidad del derecho internacional con el derecho interno en los términos de Kelsen, quien señalara que existe "una unidad epistemológica de todo el derecho, es decir, cabe concebir al derecho internacional, junto con los órdenes jurídicos particulares de cada Estado, como un sistema unitario de normas" (2011, p. 330). Queda demostrada, la primacía del derecho internacional, en la medida en la que éste ejerce una influencia sobre el derecho interno, al grado que hace que se modifique o adicione conforme a estándares internacionales.

El Estatuto de Roma de la CPI (en adelante ERCPI), al crear este tribunal internacional reconoce la existencia delitos, que por su propia naturaleza, pueden ser internacionales, como es el caso del tráfico de drogas, por lo tanto, conforme a lo señalado en el preámbulo "son una amenaza para la paz, la seguridad y el bienestar de la humanidad" y "no deben quedar sin castigo y que, a tal fin, hay que adoptar medidas en el plano nacional e intensificar la cooperación internacional para asegurar que sean efectivamente sometidos a la acción de la justicia" y en este sentido, todos los Estados deben "ejercer su jurisdicción penal contra los responsables de crímenes internacionales" (ERCPI: web).

Es decir, al considerarse al delito de tráfico de drogas como delito internacional, porque la gravedad del resultado de su comisión afecta a más de un país, se estaría procurando el bienestar de la humanidad, y por lo tanto, la obligación de perseguir y sancionar a los responsables de este delito, no solo por las autoridades nacionales, entendidas éstas, las que correspondan al sujeto 
pasivo o activo del delito, o a las del lugar de su comisión, sino además, a la CPI, la cual, conforme al artículo 1 del Estatuto de Roma "estará facultada para ejercer su jurisdicción sobre personas respecto de los crímenes más graves de trascendencia internacional de conformidad con el presente Estatuto y tendrá carácter complementario de las jurisdicciones penales nacionales" (ERCPI: web).

Es decir, no se argumenta la negación de la jurisdicción nacional para perseguir y sancionar el delito de tráfico de drogas, sino que, al considerarlo como internacional, la jurisdicción penal internacional serviría como una forma de complementar la jurisdicción nacional, consecuentemente, se mejoraría la persecución y sanción de este tipo de conductas criminales mediante la cooperación jurídica concertada entre las autoridades nacionales y la CPI; sobre todo para aquellos casos de delincuencia organizada, cuyos medios económicos, financieros, armamentistas y estructurales, exceden las capacidades de las autoridades nacionales que están imposibilitadas de atender con eficacia estas conductas criminales transnacionales, y que además, son grupos estructuralmente organizados para cometer delitos, dentro de un diseño jerárquico en donde existe una interacción constante entre los individuos que la componen, cada uno con una actividad definida dentro de la estructura, lo que hace muy complejo esta social network (Schneider et al, 2014, p. 2).

Máxime si se considera que la CPI, al ser un tribunal internacional, también aplica disposiciones penales nacionales a efecto de conocer las regulaciones que al respecto se encuentren estipuladas en las leyes nacionales penales; no solamente las que correspondan al país del que sea nacional el probable responsable, sino también las leyes de otras jurisdiccionales nacionales (Combs, 2016, p. 2) ${ }^{8}$, esto sería una aproximación positiva en materia de complementariedad (Ludwing King, 2015, p. 832); por lo tanto, la jurisdicción de la CPI sería para complementar las jurisdicción nacional.

8. La traducción es propia y la cita textual es: "Sometimes, international courts [...] apply domestic laws. When applying domestic laws, international courts sometimes apply the laws of a particular domestic jurisdiction, but at other times they apply laws that are a synthesis of a number of domestic jurisdictions. When international courts apply domestic laws, it is sometimes pursuant to express instructions in their statutes, but it is sometimes not"

\section{LA COOPERACIÓN JURÍDICA INTERNACIONAL EN MATERIA PENAL}

La eficacia del derecho internacional no sólo depende de su correcta implementación al interior de los Estados (mediante la modificación de normas constitucionales y de normas secundarias), ni de la existencia de órganos jurisdiccionales internacionales que tengan facultades para sancionar delitos internacionales, como es la CPI, además, se requieren adecuados y eficaces mecanismos de cooperación jurídica internacional. Así lo reconoce el Estatuto de Roma en su artículo 86 al señalar que "Los Estados Partes, de conformidad con lo dispuesto en el presente Estatuto, cooperarán plenamente con la Corte en relación con la investigación y enjuiciamiento de crímenes de su competencia" (ERCPI: web).

También se establecen los mecanismos que habrán de ser utilizados para lograr una cooperación en materia internacional penal, como por ejemplo, en el artículo 87 se establece la posibilidad de que la CPI solicite a los Estados partes involucrados su cooperación ya sea por la vía diplomática o por alguna otra señalada en el propio tratado; en el artículo 88 se establece la obligación de los Estados partes de crear en su derecho interno todos aquellos procedimientos que hagan posible la cooperación internacional penal; y en su caso, se obliga a las partes de este tratado a que detengan a una persona cuando así sea solicitado por la CPI y sea entregada sin demora (artículo 89 del ERCPI); inclusive, conforme lo estipulado en el artículo 90, y con base en los criterios de jurisdicción penal internacional mencionados en supralíneas, puede existir la posibilidad que una misma persona esté siendo procesada tanto por un Estado parte como por la propia CPI, en cuyo caso, se dará prioridad a la solicitud del Corte por encima del tribunal nacional; lo que prueba que la jurisdicción ejercida por tribunales internacionales tiene preeminencia sobre la jurisdicción que pueda ejercer un Estado en particular.

Ello se debe a que por la sola naturaleza de los delitos internacionales, como es el tráfico de drogas, un solo Estado es incapaz de hacerles frente eficazmente, porque el radio de afectación de este tipo de conductas criminales abarca más de un Estado, se mueve entre las fronteras, con una idea de un espacio abierto en el que tiene impacto la conducta criminal; por ende, es necesario que los Estados involucrados cooperen con la CPI a efecto de responder con mayor eficacia a la persecución y sanción de este tipo de conductas criminales. 
Se ha señalado que la "cooperación internacional entre los Estados por vía convencional es una práctica perfectamente establecida en la esfera penal; tanto en la dimensión de asegurar la aplicación del derecho penal de los ordenamientos internos, como en la dimensión de la cooperación penal internacional [...] es decir, asegurar la aplicación del propio convenio específico internacional, como vía de represión de los delitos internacionales (Badía Martí, 2008, p. 334). Eso es cierto, y una prueba de ello es el propio Estatuto de Roma, que es un tratado internacional convencional, acordado por los Estados partes para hacerle frente a conductas criminales que afectan a la comunidad internacional en su conjunto, toda vez que conforme al artículo 93 del mismo, se acordaron, vía convencional, que la cooperación incluye, entre otras cosas, identificar y buscar personas u objetos, practicar pruebas, interrogar personas, notificar documentos, trasladar personas, realizar inspecciones, practicar allanamientos y decomisos, proteger a víctimas y testigos, entre otras.

Por ello, la cooperación jurídica internacional, al ser convencional, es decir, al tener como fundamento un tratado internacional, se crea mediante acuerdos que pueden tener un alcance global, regional o particular. En el primer caso, estaríamos en presencia de tratados multilaterales con la participación mayoritaria de los miembros de la comunidad internacional, es decir, de Estados y Organizaciones Internacionales, (v.g. ERCPI); en el segundo caso, sería también tratados multilaterales pero con una aplicación específica a una determinada región del planeta (v.g. Convención Interamericana sobre Extradición); y en el tercer caso, la cooperación jurídica internacional en materia penal también se pude establecer en tratados bilaterales (v.g. Tratado de Extradición entre México y Estados Unidos de América); en todos los casos, la cooperación sería propiciada por un instrumento internacional en particular, ya sea que el resultado del delito tenga alcances globales, regionales, o que sólo afecte a dos países en particular; en cualquiera de las tres situaciones, se tendrán que considerar las diferentes formas y mecanismos de cooperación jurídica internacional que establezcan los tratados, pues éstos son la expresión máxima de un acuerdo de voluntades en materia internacional penal.

\section{CONCLUSIONES}

La hipótesis de esta investigación es que cuando el delito de tráfico de drogas trascienda las fronteras nacionales y sea realizado por la delincuencia organizada debe ser considerado como internacional, bajo la tipificación de lesa humanidad, por lo que la Corte Penal Internacional tendrá facultades de persecución y sanción de aquellas conductas graves de tráfico de drogas; para con ello hacerle frente de una manera más efectiva a la criminalidad internacional, productora de violencia y corrupción que afecta de manera sistemática y permanente a la sociedad internacional.

El paradigma consistente en que la mejor forma de ejercer el poder punitivo era única y exclusivamente de la competencia del Estado, ha sido superada, dado que por los efectos negativos de la globalización, la delincuencia organizada se ha especializado en delitos específicos, como lo es el de tráfico de drogas, no sólo por el poder económico del que disponen, sino también por la propia incapacidad del orden jurídico nacional de hacerle frente a este tipo de criminalidad internacional.

Esta aportación establece que el Estado no debe renunciar o ser suplantado en el ejercicio de sus competencias para detener y contrarrestar los efectos negativos ocasionados por la comisión del delito de tráfico de drogas; al contrario, se busca que el Estado siga teniendo competencia para perseguir y sancionar este tipo de conductas, pero cuando éstas sean realizadas por la delincuencia organizada y trasciendan las fronteras nacionales, se tipificará como internacional.

Cada caso de tráfico de drogas será evaluado para determinar si reúne los dos requisitos propuestos (caso por caso), y de ser así, serían de la competencia de la Corte Penal Internacional, y serán aquellos casos en los que las instancias gubernamentales, como la mexicana, sean incapaces de enfrentar con éxito a la delincuencia organizada transnacional. 


\section{REFERENCIAS BIBLIOGRÁFICAS}

- AMBOS, Kai (2005). La Parte General del Derecho Penal Internacional. Bases para una elaboración dogmática. Uruguay: Duncker \& Humblot, Konrad Adenauer Stiftung y Temis Editoriales.

- (2010). Fundamentos y Ensayos Críticos de Derecho Penal y Procesal Penal. Lima: Palestra Editores.

- (2013). Treatise on International Criminal Law, Volume I: Foundations and General Part. United Kingdom: Oxford University Press.

- AMBOS, Kai, MALARINO, Ezequiel \& WOISCHNIK, Jan (2005). Temas Actuales de Derecho Penal Internacional.Contribuciones de América Latina, Alemania y España. Berlin-Uruguay: Konrad Adenauer Stiftung

- BADIA MARTÍ, Anna (2008). "Cooperación Internacional en la lucha contra la delincuencia organizada transnacional", pp. 319-343. En BONET PÉREZ, Jordi y HABELLAN HONRUBIA, Victoria (eds.) La incidencia de la mundialización en la formación y aplicación del derecho internacional público, Barcelona: J.M. Bosch Editor.

- BRUS, Marcel (2014). "Ius Humanitatis and the Right to Reparation for International Crimes in Foreign Domestic Courts", International Criminal Law Review, No. 14, pp. 358-376.

- COMBS, Nancy Amoury (2016), "Seeking Inconsistency: Advancing Pluralism in International Criminal Sentencing". The Yale Journal of Internacional Law, Vol 41, number 1, pp. 1-49.

- Código Penal Federal (CPF); extraído desde http://www.diputados.gob.mx/ LeyesBiblio/pdf/9_210618.pdf; en fecha $1 / \mathrm{X} / 2018$.

- Convención Interamericana sobre Extradición. Consultada desde: https://www.oas.org/juridico/mla/sp/ traites/sp_traites-ext-interam.pdf; el
20-IX-2016.

- Convención Única de 1961 sobre Estupefacientes y su Enmienda por el Protocolo de 1972 (CUSEyEP). Extraída desde https://www.incb.org/documents/ Narcotic-Drugs/1961-Convention / convention_1961_es.pdf; el 12/VII/2018.

- Constitución Política de los Estados Unidos Mexicanos (CPEUM) Extraída desde: www.ordenjuridico.gob.mx, el 12-VII-2018.

- Convención de Viena sobre el Derecho de los Tratados (CVSDT). Extraída desde: www.ordenjuridico.gob.mx, el 12-VII-2016.

- Convención de las Naciones Unidas contra la Delincuencia Organizada Transnacional (Convención de Palermo- CNUCDOT). Extraída desde: http://www.un.org/es/ conf/conv2000/, el 28-IX-2017.

- Convención de las Naciones Unidas Contra el Tráfico Ilícito de Estupefacientes y Sustancias Psicotrópicas (CNUCTIESP). Extraída desde: http://www.un.org/es/ conf/conv2000/, el 28-IX-2018.

- CUENCA CUERBELO, Salvador (2013). "Narcotráfico: ¿Un crimen de lesa humanidad en el estatuto de Roma de la Corte Penal Internacional?", Anuario IberoAmericano de Derecho Internacional Penal, ANIDIP, vol. 1, pp. 105-134.

- Decreto por el que se adiciona el artículo 21 de la Constitución Política de los Estados Unidos Mexicanos, Diario Oficial de la Federación del 20 de junio del 2005, consultado desde www.ordenjuridico.gob. $\mathrm{mx}$, el 12-VIII-2016.

- Decreto de Promulgación del Estatuto de Roma de la Corte Penal Internacional, Diario Oficial de la Federación del 31 de diciembre del 2005, consultado desde www. ordenjuridico.gob.mx, el 12-VIII-2016.

- DE GUZMAN, Margaret M. (2016). "International Justice for Them or Global Justice for Us?: The U.S. as a Supranational 
Justice Donor", Case Western Reserve Journal of International Law, NO. 48, pp. 177-188.

- Diccionario de la Real Academia Española (RAE). Extraído desde https://dej.rae.es/ lema/trafico en fecha 12/II/2019.

- Estatuto de Roma de la Corte Penal Internacional (ERCPI). Extraída desde https://www.un.org/spanish/law/icc/ statute/spanish/rome_statute(s).pdf, 12/II/2019.

- FERRAJOLI, Luigui (2006) "Criminalidad y Globalización", Boletin Mexicano de Derecho Comparado, Num. 115, año XXXIX, enero-abril de 2006, pp. 301-316.

- FRY, Elinor (2015). "International Crimes and Case Demarcation: What are we trying to prove?, Florida Journal of International Law, Vol. 27, pp. 163-212.

- GUERRERO AGRIPINO, Luis Felipe (2011). "Delincuencia Organizada: Una Amenaza Emergente para el Estado Mexicano", Letras Jurídicas, Num. 12, pp. 1-35.

(2012). La delincuencia organizada. Algunos aspectos penales, criminológicos y político criminales, México: Editorial UBIJUS.

- HÄBERLE, Peter (2000). Teoría de la Constitución como Ciencia de la Cultura. Madrid: Tecnos.

- KALA, Julio Cesar y MARTÍNEZ, Silverio (2011). "Consecuencias jurídicas derivadas de los delitos que son competencia de la Corte Penal Internacional", De Jure, No. 6, Tercera Época, pp. 21-49.

- KELSEN, Hans (2011). Teoría Pura del Derecho, 16ํㅡㄹ Edición. México: Editorial Porrúa.

- LUDWING KING, Elizabeth B. (2015). "Big Fish, Small Ponds: International Crimes in National Courts". Indiana Law Journal, Vol. 90, PP. 829-849.

- Ley General de Salud (LGS). Extraída desde http://www.diputados.gob.mx/ LeyesBiblio/pdf/142_241218.pdf; el 12/ II/2019.

- MEJÍA AZUERO, Jean Carlo (2008). "Diferencias entre Derecho Penal Internacional y el Derecho Internacional Penal", Prolegómenos. Derechos y Valores, vol IX, num. 22, pp. 181-217.

- SCHNEIDER, Eder Milton, IGLESIAS, José Roberto, HALLBERG, Karen, KUPERMAN, Marcelo Nestor (2014). "Crimes Against Humanity: The Role of International Courts", PLoS ONE, Public Library of Science, Volume 9, Issue 6, pp. 1-8.

- United Nations Office on Drugs and Crime (UNODC). Global Overview of Drug Demand and Supply. Lattest Trends, cross-cutting issues. World Drug Report 2018, Vol. 2. Extraído desde https://www.unodc.org/ wdr2018/prelaunch/WDR18_Booklet_2_ GLOBAL.pdf; en fecha 23/VII/2019. 